\title{
EXPANSÃO DO ENSINO MÉDIO: TEMORES SOBRE A EDUCAÇÃO DE JOVENS E ADULTOS
}

\author{
CANDIDO ALBERTO GOMES \\ clgomes@terra.com.br
}

\author{
BEATRICE LAURA CARNIELLI \\ beatrice@pos.ucb.br \\ Universidade Católica de Brasília e Unesco
}

\begin{abstract}
RESUMO
A expansão do ensino médio tem-se realizado crescentemente, em termos relativos, pela educação de jovens e adultos - EJA -, reacendendo temores de facilitário educacional. Estes, porém, não são confirmados pelas estatísticas educacionais, que indicam a persistência da grande maioria dos alunos no ensino médio regular, especialmente noturno, apesar da elevada distorção idade-série. Para melhor conhecer as trajetórias e motivações dos estudantes, foi realizada uma pesquisa por meio de grupos focais junto a alunos das duas modalidades de educação no Distrito Federal. Os resultados indicam que os participantes consideravam estigmatizados os certificados de EJA e que preferiam alternativa mais exigente, com melhores perspectivas para o trabalho e a continuidade dos estudos. Assim, é confirmada a estratificação das oportunidades educacionais, formando um cardápio pelo qual modalidades diferentes têm custos e benefícios diversos. A dualidade dos sistemas torna a EJA, com menos recursos e prestigio, uma alternativa negligenciada de democratização.

ENSINO MÉDIO - EDUCAÇÃO DE JOVENS E ADULTOS - DEMOCRATIZAÇÃO DO ENSINO - ENSINO NOTURNO
\end{abstract}

\section{ABSTRACT}

SECONDARY EDUCATION EXPANSION: FEARS ON ADULT EDUCATION. Secondary education in Brazil has expanded increasingly in relative terms by means of adult education. This fact has risen fears of lower academic requirements. However, statistics do not confirm it, since most of the students stay at regular night schools much later than the age limit. A

Este artigo contou com a colaboração de Alda Lino dos Santos Pereira, Katia Tomaz Fernandes, Márcia Lucindo de Amorim, Marli Alves Flores Melo, Marly Marun, Patrícia Teixeira de Almeida, Sandra Maria de Medeiros, (mestrandas em Educação da Universidade Católica de Brasília) e Isolêta Rodrigues Assunção (aluna do Curso de Graduação em Educação da Universidade Católica de Brasília). Os autores e colaboradores agradecem à Professora Miriam Abramovay as orientações sobre grupos focais. 
research project based on focal groups gathered data on students in both regular and adult education. Results show that adult education certificates are stigmatized so that night school students had chosen more demanding schooling, with better perspectives for work and higher education. Therefore, educational opportunities are stratified, similar to a menu composed of cheap and expensive alternatives, with corresponding benefits. The dual educational system and the adult education fragility makes the latter a neglected and underused alternative for democratization of educational opportunity.

DEMOCRATIZATION OF EDUCATION - SECUNDARY EDUCATION - EVENING COURSES

Um dos fatos marcantes da recente história da educação brasileira é a expansão do ensino médio. Com a melhoria do fluxo dos discentes no ensino fundamental, rumamos, como outros países em desenvolvimento, para o ensino médio de massa, ou para a progressiva universalização do ensino médio gratuito, na expressão constitucional. Esta nova realidade traz novos desafios, como as necessidades de superar a inadequada educação acadêmica tradicional e de atender a um leque muito mais amplo de diversidades, num contexto de rápida mudança econômica, cultural e social, além de assegurar maior qualidade (Unesco, 200 I), em vez de se oferecer um prolongamento "aguado" do nível de ensino anterior. Uma recente preocupação, aliás periodicamente renovada, é com o crescimento da matrícula da educação de jovens e adultos, que poderia concorrer com o ensino regular. Os dados aqui apresentados, entretanto, mostram outro panorama: o de uma concorrência já conhecida entre ambos, em que, apesar dos temores, inclusive da redução das idades mínimas pela atual Lei de Diretrizes e Bases, o ensino regular noturno ainda é uma área de amplas dimensões e alta atração, ao passo que a educação de jovens e adultos constitui, pelas dificuldades que tem vivido, uma alternativa negligenciada de democratização educacional. O que levaria, pois, os alunos a preferirem, em numerosas situações, o ensino regular noturno à educação de jovens e adultos, apesar das vantagens desta última em termos de duração e flexibilidade? Que vantagens e desvantagens apresentam uma e outra? Seria a certificação mais facilitada uma atração irresistível? Estas são algumas perguntas a que se busca responder, abrindo a caixa-preta da opinião dos discentes, o que conduz, entre outras, a uma indagação: a educação brasileira tem tido maior interesse em manter um cardápio variado para atender a diferentes clientes, num sistema segmentado e estratificado, ou tem realizado a concretização de oportunidades educacionais democráticas, segundo os objetivos da "educação para todos", subscritos legalmente pelo país? 


\section{UMA EDUCAÇÃO ESTRATIFICADA}

O paradigma do conflito em sociologia da educação tem apontado para a estratificação e segmentação dos sistemas educacionais, à imagem e semelhança da estratificação das suas sociedades. A teoria da reprodução apontou para o controle pelos grupos e classes dominantes dos significados legítimos e socialmente mais valorizados que intermedeiam as relações de poder. Desse modo, sob a veste da meritocracia, a escolarização é a base para uma mobilidade social limitada, na qual têm maior vantagem os que possuem capital cultural (Bourdieu, Passeron, 1970). A teoria da correspondência, por sua vez, ainda que com grandes limitações destacou que as relações sociais de produção determinam as relações sociais de educação, de tal modo que resulta em uma socialização diferenciada dos alunos, isto é, alunos destinados a diferentes classes sociais recebem escolaridades de tipos diversos (Bowles, Gintis, 1977). A sociologia do currículo, afinal, voltando-se para a escola e para a sala de aula, denunciou que este é uma seleção de conhecimentos aprovados pela sociedade e distribuídos a diversos grupos sociais em diferentes teores e dosagens. Os conhecimentos passam por sucessivos filtros até comporem os currículos escolares: a definição de conhecimento, a escolha de conteúdos da cultura, a estratificação dos conteúdos, a organização curricular e a distribuição aos diferentes grupos de estudantes (Young, 1971, 1988; Bernstein, 1977, 1990; Câmara, 2000). Com isso, o conhecimento socialmente estratificado (quanto mais abstrato e erudito, mais alto o status) dá origem a currículos e a sistemas educacionais também estratificados, com diferentes trajetórias dos estudantes no seu âmbito. Por fim, os neoweberianos consideram que a educação pode servir de marca de identificação de um grupo de status, assim como critério de seleção que não está necessariamente ligado à competência. Desse modo, o diploma nas sociedades burocráticas pode criar privilégios análogos aos da aristocracia. Trata-se de credenciais, utilizadas como moeda para obter empregos, e de meios de seleção cultural, no processo de competição entre os grupos sociais. Desse modo, os sistemas escolares são burocracias nas quais, como numa arena, se desenrola continuamente o drama da luta entre grupos e indivíduos pela riqueza, prestígio social e poder (Weber, 1968; Collins, 1979).

Embora superados o pessimismo e o fatalismo que supunham ser a educação enformada irresistivelmente pela estratificação social, como barro mole num rígido molde, reconhece-se que os sistemas escolares e as credenciais que emitem são diversificados e se hierarquizam ante as disputas da sociedade global, ao mesmo tempo que contribuem para o seu resultado (Gomes, 1994). Trata-se de arenas onde se estabelecem relações e inter-relações de maneira pouco conhecida e 
onde têm lugar conceitos como os de resistência e de relativa autonomia da escola (Giroux, 1986; Snyders, 1974; Morrow, Torres, 1995). Essa herança teórica diversificada, em suma, reitera a estratificação interna da educação. Não só os componentes curriculares têm status diferenciado, conforme já referido, como também as opções, a exemplo do ensino acadêmico e profissionalizante, ou, ainda, modalidades como, na legislação nacional, de ensino regular e educação de jovens e adultos. Esta última, como educação de segunda oportunidade, destina-se aos alunos considerados "mais fracos", defasados e menos privilegiados dos pontos de vista social e educacional. Não é de surpreender, portanto, que aos seus certificados possa ser atribuído estigma de inferioridade, pressupondo que o portador não se deu bem no ensino regular.

Em conseqüência dessa estratificação, a alocação interna de recursos sofre distorções. Sendo burocracias, pode-se afirmar, conforme a tradição weberiana, que os sistemas escolares são âmbitos de luta nos quais se disputam recursos, prestígio social e poder, e nos quais o valor dos diversos tipos de serviços prestados influencia os meios obtidos, assim como as instituições são contagiadas pelo status dos seus beneficiários. Daí fatos amplamente conhecidos em nosso meio, como a alocação de professores cedidos, a improvisação no uso de instalações do ensino regular, as limitações ao uso de determinados equipamentos próprios também do ensino regular, como laboratórios, tanto na educação de adultos, como no ensino noturno.

Em outra latitude teórica, texto clássico de Clark (1978) destaca de modo lúcido as relações entre a adaptação das organizações e os valores precários, no caso da educação de adultos, ainda que o meio e certas condições sejam em parte diferentes do Brasil. Os valores sociais tendem a ser precários quando não são definidos, isto é, quando não são incorporados claramente a objetivos e padrões existentes de grupos comprometidos. A organização fica sujeita a dilemas e impasses na transformação dos seus valores iniciais no processo de justaposição a problemas emergentes. A educação de adultos tem valores precários por eles serem menos aceitáveis por uma parte da população. Sendo educação de segunda oportunidade, para alunos fora da faixa etária, constitui atividade menos vinculada ao propósito primário da educação. Ela é menos estruturada, até por força da flexibilização necessária ao atendimento das necessidades dos alunos; o ensino não é compulsório, por haver sido ultrapassada a faixa de idade da obrigatoriedade escolar; sua procura é voluntária, com o sustento dependente das oscilações do número de alunos; seus objetivos em parte são menos claros, por incluir não só a educação de segunda oportunidade, mas também a educação continuada. Essa precariedade de valores resulta num grau de legitimidade mais baixo que o do ensino regular, numa posição 
relativamente marginal no âmbito da organização, na maior dificuldade de obter recursos e na elevada vulnerabilidade a cortes orçamentários.

\section{MAZELAS HISTÓRICAS}

Retrospectiva da pesquisa dos anos 70 e 80 sobre o então ensino supletivo no Brasil (Haddad, 1987) sugere que as políticas públicas eram perpassadas pela preocupação com a dualidade de sistemas educacionais, de modo a evitar a diferenciação entre a "escola para os nossos filhos" e "os filhos dos outros". Tendo como um dos valores subjacentes a igualdade de oportunidades educacionais, temia-se a concorrência entre o ensino regular e o supletivo, em especial a fuga de alunos do primeiro para o segundo, que poderia exercer o papel de "facilitário". Por isso, a reforma de 1971, além de elevar as idades mínimas para os exames supletivos (de 16 e 19 para 18 e 21 anos, respectivamente, para o ensino de $1^{\circ}$ e $2^{\circ}$ graus), buscou constituir uma nova concepção de escola, que poderia modernizar o ensino regular pelo seu exemplo e pela interpenetração esperada entre os dois sistemas.

Os resultados das pesquisas, entretanto, não indicam êxito notável na integração ou interpenetração desses dois sistemas, nem na suposta ação modernizadora que o supletivo poderia exercer sobre o regular. Igualmente, parece ter continuado a haver competição entre ambos e facilidades por parte do primeiro. Todavia, não se confirmaram os temores de esvaziamento, visto que houve grande incremento, sucedido por significativa diminuição da procura dos exames supletivos na própria década de 70.

Em contrapartida, a maioria dos pesquisadores concluiu que o ensino supletivo, via exames, reproduzia uma série de mecanismos seletivos da escola regular, limitando a sua função democratizadora. $\bigcirc$ alunado, predominantemente até 25 anos de idade, com apenas $6 \%$ tendo pais com ocupações manuais não qualificadas, de vivências urbanas e tendo com freqüência ampla escolaridade regular anterior, não parecia diferir substancialmente da população do ensino médio regular, a não ser no nível de escolaridade mais baixo dos pais e na alta proporção de trabaIhadores estudantes. $O$ perfil dos alunos dos cursos de suplência também era em parte semelhante. Em sua maioria jovens, migrantes e trabalhadores, com experiência prévia no ensino regular, os pais predominantemente tinham ocupações manuais. De qualquer modo, os cursos não se adequavam às necessidades do seu público, pela falta de apoio e assistência, pela falta de preparação dos docentes e pelas metodologias utilizadas. 
As pesquisas recentes (Haddad et al., 2002), talvez mais interpretativas, permitem concluir que a escola permanece reproduzindo uma estrutura de desigualdades sociais, por meio da repetência, da evasão e do fracasso. As camadas populares continuam a dispor do ensino noturno e da educação de jovens e adultos, porém ambos se caracterizam pela sua condição periférica. A escola noturna é marginalizada e a ela se estendem "as mazelas do ensino diurno de modo mais agravado e cumprindo as funções de seletividade e hierarquização social comumente identificadas na escola" (Haddad et al., 2002, p. 96). Ela é a última opção de trabalho dos professores, o que, inclusive, não permite a constituição de uma identidade com a realidade da escola. Por seu lado, a educação de jovens e adultos também continua a ter condição marginal, seja no interior da unidade escolar, estigmatizada como o turno da evasão, seja no interior das secretarias de educação, pelo descompromisso. Trata-se de um sistema paralelo, independente e inferior ao sistema regular, que reproduz os mesmos elementos denunciados em outros sistemas de ensino, isto é, a seletividade, a exclusão, o autoritarismo e o ensino precário, mnemônico e centrado na subordinação do educando como objeto passivo. Ainda assim, ampliaram-se no período as oportunidades educacionais para jovens e adultos, conquanto, segundo algumas pesquisas, isso não modifique a hierarquia social pré-existente.

Muitos alunos internalizam essa situação de inferioridade, considerando-se incapazes e fracos. Sua visão de educação é individualista e utilitarista, esperam que a escola certifique e prepare para o trabalho. Grande parte do alunado continua a ser composta por pessoas que já experimentaram o fracasso escolar e que já assimilaram valores socialmente difundidos em relação ao papel da educação formal, de tal modo que vêem os centros de estudos supletivos como credenciadores. Igualmente, questionam os cursos e exames, notoriamente a sua qualidade, o seu curto tempo, as suas metodologias individualizantes e a falta de preparo de professores e alunos. Isso significa que três decênios de políticas educacionais não solucionaram os problemas de democratização educacional, continuando em grande parte as mesmas linhas diferenciadoras. Também, persistem os impasses entre as características propedêuticas do ensino médio e as relações com o trabalho ou a formação profissional.

\section{CONCORRÊNCIA ENTRE ENSINO REGULAR E EJA}

As estatísticas educacionais dos últimos anos parecem corroborar a velha tese do esvaziamento do ensino regular pela educação de jovens e adultos, em que pesem 
as grandes mazelas apontadas pelo corpo de pesquisas mencionado. Com efeito, de 1997 a 200 I, o ensino médio regular teve aumento de 31, I \% da matrícula; os cursos presenciais de nível médio com avaliação no processo, educação de jovens e adultos, 152,6\%, e os cursos preparatórios para exames, $618 \%$ (Gomes, Carnielli, Assunção, 2002). No ensino fundamental, no mesmo interstício, o crescimento das duas modalidades - ensino regular e educação de jovens e adultos - não distou muito, podendo-se chegar à conclusão de que as pressões da inflação educacional e do aumento dos requisitos educacionais para as ocupações estariam levando a população, no nível médio, a buscar a educação de jovens e adultos (por exemplo, Filmus et al., 2002). Os números absolutos, por trás dos percentuais, no entanto, retocam essa imagem: na verdade, em 1997, o ensino médio regular tinha 6.405.057 alunos; os cursos presenciais com avaliação no processo, apenas 390.925 alunos e os cursos preparatórios para exames, modestos 17.234 matriculados. Quatro anos depois, esses números passaram a ser, respectivamente, 8.398.008, 987.376 e 123.742. Assim, houve um incremento percentual elevado ante uma base pequena, escolhida por haver sido o primeiro ano em que essas matrículas foram integralmente desagregadas pelos censos escolares. Todavia, as matrículas da educação de jovens e adultos mantinham modesta participação em face do ensino regular.

Efetivamente, a tabela I mostra que, apesar do aumento dos efetivos discentes, a educação de jovens e adultos representava pouco diante dos números do ensino regular. No caso do ensino médio, nível que mais cresceu, a razão quase dobrou nos cursos presenciais com avaliação no processo entre 1997 e 200 I (para cada grupo de 100 alunos no ensino médio regular encontram-se aproximadamente 12 alunos na EJA) e mais que dobrou quando se tomou o total da educação de jovens e adultos, incluindo o alunado dos cursos preparatórios de exames (para cada 100 alunos no ensino médio regular, encontram-se 13 na EJA). A participação da educação de jovens e adultos foi menor nas séries iniciais do ensino fundamental, mais distante desses limites de idade estabelecidos por lei, e aumentou nos níveis posteriores, mais próximos desses limites. De modo geral, a proporção de alunos da educação de jovens e adultos tem sido muito modesta numa população nacional subescolarizada, cuja média de anos de estudo está abaixo do mínimo obrigatório.

Oferecendo uma dimensão das relações entre o ensino regular e a educação de jovens e adultos, a tabela 2 apresenta a distribuição percentual de cada grupo etário segundo o nível de ensino e a modalidade de educação. Em primeiro lugar, aparece em negrito a elevada proporção de alunos defasados em relação ao nível de ensino, no processo de atraso conhecido como pedagogia da repetência. 
RAZÃO ENTRE NÚMERO DE MATRÍCULAS NA EDUCAÇÃO DE JOVENS E ADULTOS E DO ENSINO REGULAR, SEGUNDO O NÍVEL DE ENSINO E MODALIDADE DE EDUCAÇÃO (BRASIL , 1997 A 200I)

\begin{tabular}{|c|c|c|c|c|c|}
\hline \multirow[t]{2}{*}{ Níveis de ensino e modalidades de educação } & \multicolumn{5}{|c|}{ Anos } \\
\hline & 1997 & 1998 & 1999 & 2000 & 2001 \\
\hline Ensino médio & 6,4 & 8,4 & 10,0 & 12,3 & 13,2 \\
\hline Ensino fundamental & 6,6 & 6,1 & 6,2 & 6,7 & 7,9 \\
\hline \multicolumn{6}{|c|}{ Cursos presenciais com avaliação no processo - ensino regular } \\
\hline Ensino médio & 6,1 & 7,4 & 8,5 & 10,7 & 11,8 \\
\hline Ensino fundamental $\left(5^{a}-8^{a}\right)$ & 9,6 & 9,0 & 8,6 & 9,2 & 9,5 \\
\hline Ensino fundamental $\left(\left.\right|^{\mathrm{a}}-4^{\mathrm{a}}\right)$ & 4,4 & 3,7 & 3,9 & 4,2 & 5,8 \\
\hline
\end{tabular}

Fonte dos dados originais: Censos escolares (Brasil, 1998, 1999, 2000, 200 Ia, 2002).

Com efeito, o tempo médio esperado para conclusão tem caído, ainda que em ritmo relativamente lento, indicando o reordenamento dos fluxos escolares. No ensino fundamental, o tempo médio esperado para conclusão, entre 1995 e 1999 , declinou de I I,3 anos para 10, I, ao passo que o número médio esperado de séries concluídas passou, no mesmo período, de 6,2 anos para 6,6. No ensino médio, o número médio esperado de séries concluídas, que era de 2,3 anos em 1995, passou a 2,7 em 1999 (Brasil, 200 la).

Observa-se, ainda na tabela 2 , que elevada proporção dos alunos do ensino fundamental, já defasados em termos de idade (56,7\% do grupo de 15 a 17 anos), mantinha-se no ensino regular e só 4,8\% achavam-se na educação de jovens e adultos. Ainda, 30,8\% dos alunos de 18 a 24 anos estavam matriculados no ensino fundamental regular, assim como 27,2\% do grupo de 25 a 29 anos e 25,5\% do grupo de 30 anos e mais. No ensino médio, a maioria do grupo etário de 18 a 24 anos (53,3\%), já francamente defasado e em idade de freqüentar a educação de jovens e adultos, permanecia no ensino médio regular. Na faixa de 25 a 29 anos a maior proporção $(29,4 \%)$ também permanecia no ensino médio regular, assim como 17,6\% do grupo de 30 anos e mais. Dessa forma, parece manifestar-se uma retenção marcante de grupos de idade elevada no ensino regular, sem se transferir para a educação de jovens e adultos, apesar da faculdade legal. Sendo a opção voluntária, parte ponderável do alunado elege a permanência no ensino regular, apesar da seriação, do custo de oportunidade resultante da idade mais avançada e outros possíveis fatores. 
TABELA 2

\section{DISTRIBUIÇÃO PERCENTUAL DA POPULAÇÃO MATRICULADA, POR NÍVEL DE ENSINO E MODALIDADE DE EDUCAÇÃO, SEGUNDO GRUPOS DE IDADE (BRASIL, 2000)}

\begin{tabular}{l|r|r|r|r|c}
\hline \multirow{2}{*}{$\begin{array}{c}\text { Nível de ensino e modalidade } \\
\text { de educação }\end{array}$} & \multicolumn{5}{|c}{ Grupos de idade } \\
\cline { 2 - 6 } & Até 14 & 15 a 17 & 18 a 24 & 25 a 29 & 30 e mais \\
\hline EF Regular & 99,5 & 56,7 & 30,8 & 27,2 & 25,5 \\
EM Regular & 0,2 & 37,8 & 53,3 & 29,4 & 17,6 \\
Alfabetização EJA & 0,0 & 0,2 & 0,5 & 1,9 & 4,7 \\
EF EJA & 0,3 & 4,8 & 10,5 & 27,0 & 36,0 \\
EM EJA & 0,0 & 0,5 & 4,9 & 14,5 & 16,2 \\
Total & 100 & 100 & 100 & 100 & 100 \\
Matríc. população recenseada & 101,3 & 83,3 & 31,3 & 8,6 & 2,5 \\
\hline
\end{tabular}

Fontes dos dados originais: Censos Escolares (Brasil, 2002, FIBGE, 2003).

Obs.: EF - ensino fundamental; EM - ensino médio; EJA - educação de jovens e adultos.

- Números em negrito: percentuais de alunos defasados em termos de série-idade.

- Número superior a 100 pela inclusão de alunos de menos de sete anos de idade.

Ademais, comparando os grupos de estudantes por idade com a população nacional recenseada, verifica-se que o agrupamento de 7 a 14 anos estava praticamente todo na escola. Dos 15 aos 17 anos, 83,3\% estavam matriculados, porém só $38,3 \%$ no nível de ensino adequado, isto é, no ensino médio regular ou na modalidade educação de jovens e adultos. Já o grupo de 18 a 24 anos, correspondente em princípio aos cursos superiores de graduação, estava majoritariamente no ensino fundamental (total de 4 I ,8\%) e no ensino médio (total de 58,2\%). Como se considera a educação básica, não foram incluídos os matriculados em nível superior, cuja faixa etária não é sempre determinada. Conclui-se, assim, que, apesar do seu baixo nível médio de escolaridade, a população brasileira permanece longo tempo na escola, persiste nela e opta pelo ensino regular, mesmo fora da idade. Conforme foi assinalado, a população brasileira em geral manifesta indícios de confiança e persistência na escolaridade, tanto que, no ensino fundamental, as perdas maiores, ao contrário do que se julgava, ocorrem pela repetência e não pela evasão (Fletcher, Ribeiro, 1987).

Otraso crônico, em grande parte provocado pelo baixo grau de eficiência do sistema, com altas taxas de reprovação e de afastamento por abandono, representa, portanto, perdas econômicas e sociais notáveis. Para atestar isso, basta ob- 
servar os números absolutos. O Brasil tinha, em 2000, 9.425. I 30 alunos de I 5 a 17 anos nas escolas, na faixa correspondente, sem atrasos, ao ensino médio. Considerando que, pelo censo demográfico de 2000, a população dessa faixa era de 10.702.499 habitantes, se não houvesse distorção série-idade, quase toda essa população estaria não só na escola, mas também concluindo o ensino médio aos 17 anos de idade. Em outras palavras, a escolarização da faixa etária seria de 88, 1 \%, próxima da dos países desenvolvidos. Além disso, a escolarização do grupo de 18 a 24 anos na educação básica era de 31,3\%. Se esses jovens que ainda se encontravam na educação básica estivessem em cursos superiores, estaria ultrapassada a meta correspondente do Plano Nacional de Educação para 20 I (Brasil, 200 I). Portanto, o Brasil, se contasse com uma educação plenamente eficiente, com os fluxos discentes ordenados, seria um país com escolaridade fundamental universalizada, quase $90 \%$ dos adolescentes no ensino médio e pelo menos um terço da população jovem na educação superior. Assim, existem muito mais vagas ocupadas que crianças e jovens, evidenciando enorme desperdício de vidas e recursos. É bem verdade que pode haver alta eficiência sem elevados graus de qualidade e democratização, embora o contrário seja extremamente difícil, para não dizer impossível.

Buscando conhecer, ainda, quais os públicos do ensino regular e da educação de jovens e adultos, a tabela 3 focaliza a distribuição etária do alunado por nível de ensino e modalidade de educação. Considerando que a idade recomendada de conclusão do curso médio é de 17 anos, mais da metade dos alunos estava atrasada. Mais ainda, pode-se considerar que essa elevada proporção estava à beira da idade mínima legal de conclusão do curso médio, podendo deslocar-se, caso desejasse, para a educação de jovens e adultos. Os números se mantiveram estáveis no período observado, talvez com tendência de declínio ao final, o que pode indicar que a educação de jovens e adultos estaria tomando o seu lugar. Como o ensino médio é o desembocar da educação básica, as repetições e abandonos se acumulam, gerando números típicos de sistemas educacionais com amplo acesso, mas com dificuldades na eficiência e na qualidade.

Por sua vez, a educação de jovens e adultos no mesmo nível médio apresentava uma proporção mais elevada de alunos mais velhos. Embora os limites estabelecidos pelos censos escolares sejam diversos daqueles do ensino regular e tenham variado ao longo da série histórica analisada, a proporção de alunos defasados era muito superior, até por imposição legal. Ou seja, por um lado, o ensino regular abrigava a maioria de alunos com distorção série-idade, enquanto, por outro, a educação de jovens e adultos, segundo o seu caráter, era o locus legal por excelência 
TABELA 3

DISTRIBUIÇÃO PERCENTUAL DAS MATRÍCULAS POR FAIXA DE IDADE, SEGUNDO O NÍVEL DE ENSINO E MODALIDADE DE EDUCAÇÃO BRASIL, 1998 A 2001

\begin{tabular}{|c|c|c|c|c|}
\hline \multirow{2}{*}{$\begin{array}{l}\text { Matrícula por níveis, } \\
\text { modalidades e idade }\end{array}$} & \multicolumn{4}{|c|}{ Anos } \\
\hline & 1998 & 1999 & 2000 & 2001 \\
\hline \multicolumn{5}{|l|}{ Ensino médio regular } \\
\hline 18 anos e mais & 53,8 & 55,2 & 55,7 & 53,8 \\
\hline \multicolumn{5}{|l|}{ Ensino médio, EJA* } \\
\hline I 8 anos e mais... & ... & 95,2 & $\ldots$ & \\
\hline 19 anos e mais & 87,0 & $\ldots$ & $\ldots$ & 96,3 \\
\hline 20 anos e mais... & 83,2 & $\ldots$ & $\ldots$ & \\
\hline \multicolumn{5}{|l|}{ Ensino fundamental regular } \\
\hline 15 anos e mais & 23,7 & 23,5 & 23,5 & 22,5 \\
\hline \multicolumn{5}{|l|}{ Ensino fundamental, EJA* } \\
\hline I8 anos e mais... & $\cdots$ & 76,6 & 83,8 & \\
\hline 19 anos e mais & 61,7 & ... & ... & ... \\
\hline 20 anos e mais... & 61,4 & $\ldots$ & $\ldots$ & \\
\hline
\end{tabular}

Fonte dos dados originais: Censos Escolares (Brasil, 1998, 1999, 2000, 200 Ia).

*Cursos presenciais com avaliação no processo.

Obs.: em EJA os grupos de idade variam conforme o ano do Censo Escolar.

para os que buscavam uma segunda oportunidade de escolarização. Isso aparentemente, pois havia uma superposição de funções entre o ensino regular e a educação de jovens e adultos, uma espécie de zona cinzenta, pela qual ambos recebiam alunos que se atrasavam na escolaridade. A proximidade entre os percentuais de alunos acima de 17 anos de idade no ensino médio regular e no período noturno sugere que o ensino médio regular à noite, ainda que geralmente seriado, pode estar abrigando alunos que poderiam estar na educação de jovens e adultos.

Uma evidência adicional da importância do ensino regular noturno é oferecida pela idade dos concluintes. No ano 2000, 67, $1 \%$ dos alunos que terminaram o ensino fundamental no período noturno tinham 18 anos e mais, ou seja, haviam superado há muito a condição de maiores de 15 anos para completar seus estudos pela educação de jovens e adultos. No caso do ensino médio a proporção de concluintes com 20 anos e mais de idade foi de 62,9\%, ultrapassando também de longe a condição de ter mais de 18 anos. 
Sendo a opção voluntária, parte ponderável do alunado, portanto, parece eleger a permanência no ensino regular, apesar da seriação, do custo de oportunidade resultante da idade mais avançada e outros possíveis fatores. Desse modo, a educação de jovens e adultos não parece estar cumprindo as suas funções, ao contrário, está constituindo uma alternativa negligenciada de democratização educacional no país. Importa, então, indagar por que os alunos parecem preferir, em maioria, permanecer no ensino regular noturno e quais as vantagens e desvantagens comparativas das duas modalidades de educação.

\section{O ESTIGMA DA EDUCAÇÃO DE JOVENS E ADULTOS}

Para explorar esta questão, foi levada a efeito uma pesquisa exploratória por meio de grupos focais em dois estabelecimentos da rede pública do Distrito Federal, ambos de grande porte e elevada reputação, o primeiro, exclusivamente de ensino médio regular, localizado numa cidade satélite, e o segundo, de educação de jovens e adultos nos níveis fundamental e médio, situado no Plano Piloto de Brasília. Foram organizados três grupos focais em cada unidade escolar, com escolha aleatória dos seus componentes. No caso do estabelecimento de ensino regular, com a ajuda da coordenação pedagógica, foram considerados como base para seleção sobretudo os alunos que antes freqüentaram a educação de jovens e adultos. A receptividade, em ambos os casos, foi muito boa, manifestando os alunos grande interesse em se expressar. Os resultados não têm a pretensão de representatividade e não podem ser generalizados, constituindo sugestão para aprofundamento em futuras pesquisas, de maior abrangência.

Os grupos focais realizados com alunos de educação de jovens e adultos foram compostos por trabalhadores estudantes, cuja atividade laboral se exercia com freqüência perto do estabelecimento. Como no corpo de pesquisas indicado, os participantes tinham em maioria até 25 anos de idade, haviam recebido escolaridade regular e carregavam longo histórico de reprovações e períodos de abandono que resultaram na defasagem etária em relação ao nível de ensino. Isso ocorreu em virtude da falta de oportunidades educacionais na área em que residiam, por proibição dos maridos, por inadequação das escolas e por "falta de interesse ou esforço", quadro este que se alterou com a sua migração para o Distrito Federal. Em sua maioria exerciam ocupações manuais, o que reflete de modo geral o modesto nível de renda dos alunos e o elevado grau de acesso ao ensino público em nível médio no Distrito Federal (Cavalcante, 2002), além possivelmente da espiral de requisitos educacionais pelo trabalho. Com efeito, apenas em caráter ilustrativo, 
convém citar que 30,4\% dos alunos do último ano do ensino médio regular em São Paulo exerciam ocupações manuais em 1963 (Dias et al., 1967). Apesar, porém, do seu modesto status, em maioria, os pesquisados haviam passado pelo funil do ensino fundamental, embora fossem quase todos alunos que haviam fracassado na escola regular e que, por algum tempo, ou não dispunham de outra oportunidade ou não tinham motivação suficiente para reencetar os estudos.

No seu contexto sociocultural, a educação de jovens e adultos representava uma alternativa importante para eles retomarem a escolaridade, cuja utilidade em termos de trabalho foi destacada, além das repercussões mais amplas, formativas e informativas, do processo educacional. Aliás, no total de menções houve mais referência às competências gerais da educação, em termos de capacidade de comunicação, conscientização e afirmaç̧ão dos direitos que à obtenção e ascensão no trabalho, embora a quantidade de referência a estas últimas fosse muito significativa:

(A educação de jovens e adultos) significa um apoio, uma chance para prosseguir o estudo.

É a única oportunidade para nós.

É uma conscientização da realidade; sem a escola tudo fica pior.

Agora posso reconhecer isso. A gente aprende com as pessoas o valor do ser humano.

É um meio de sobrevivência, é uma forma de saber falar direito, aprender a se destacar; oportunidade de encontrar um emprego decente.

Animados pelas exigências sociais e pelas necessidades de realização individual, os pesquisados buscaram o estabelecimento, numa "luta para ter um direito", tendo em vista o seu caráter público e gratuito e a flexibilidade inerente ao regime modular e semipresencial, sem freqüência obrigatória. Ao contrário do ensino regular, como assinalou uma aluna, não se perde o ano com a reprovação "numa matéria", mas se pode "refazer e avançar", ganhando tempo. Essa rapidez para certificação, aliada à facilidade em relação às exigências, constituía uma das maiores atrações, indicando o "conteúdo resumido" e a certificação mais fácil e rápida. Ao mesmo tempo, "conhecer pessoas e fazer amizades", isto é, o cumprimento do seu papel socializador pela escola, foi mencionado por vários informantes. Outras vantagens citadas foram a cantina e a cooperativa para adquirir materiais de aprendizagem. A educação de jovens e adultos era, portanto, uma forma de recuperar o tempo perdido (ver Quadro I). 


\section{SUMÁRIO DAS VANTAGENS E DESVANTAGENS DO ENSINO MÉDIO REGULAR E DA EDUCAÇÃO DE JOVENS E ADULTOS SEGUNDO OS PARTICIPANTES}

\begin{tabular}{|c|c|}
\hline Vantagens & Desvantagens \\
\hline \multicolumn{2}{|c|}{ Educação de jovens e adultos } \\
\hline $\begin{array}{l}\text { - Facilita a certificação em pouco tempo } \\
\text { - Freqüência não é obrigatória } \\
\text { - Noturna } \\
\text { - Gratuita } \\
\text { - Reprovação tem menores repercussões em } \\
\text { virtude de o ensino ser modular } \\
\text { - "Todos estão concluindo o ensino médio" } \\
\text { - Única oportunidade para quem trabalha } \\
\text { - Maior facilidade de vaga que no ensino regular } \\
\text { - Cantina } \\
\text { - Cooperativa para adquirir materiais } \\
\text { de aprendizagem } \\
\text { - Mais fácil } \\
\text { - Recupera o tempo perdido por } \\
\text { reprovações anteriores } \\
\text { - "Pressão das provas" facilita alcançar os níveis } \\
\text { estipulados de cada disciplina }\end{array}$ & $\begin{array}{l}\text { - Facilita a certificação } \\
\text { - Tempo letivo curto } \\
\text { - Não dá acesso ao PAS } \\
\text { - Não prepara adequadamente para o "vestibular' } \\
\text { - Mercado de trabalho exige maiores qualificações } \\
\text { - Estigmatizada, mercado de trabalho discrimina } \\
\text { - Não dá base para concursos públicos } \\
\text { - Depende do interesse e iniciativa do aluno } \\
\text { - "Professores não ensinam". Aprende-se mais } \\
\text { com os colegas } \\
\text { - Cansaço e stress dos professores } \\
\text { - Cooperativa vende materiais quase aos preços } \\
\text { do comércio } \\
\text { - Houve queda da qualidade nos últimos anos } \\
\text { - Superlotação de alunos } \\
\text { - Alunos estudam só para provas } \\
\text { - Melhor ensino-aprendizagem }\end{array}$ \\
\hline \multicolumn{2}{|c|}{ Ensino regular } \\
\hline $\begin{array}{l}\text { - Maior tempo letivo } \\
\text { - "Oferece mais base" } \\
\text { - Estudantes precisam ter mais compromisso } \\
\text { - Podem participar do PAS } \\
\text { - Melhor preparação para o trabalho, para os } \\
\text { estudos superiores e para os concursos públicos } \\
\text { - Mais voltado para a aprendizagem que para a } \\
\text { certificação } \\
\text { - Maior orientação } \\
\text { - Professores mais qualificados } \\
\text { - Desigualdade de tratamento em relação ao }\end{array}$ & $\begin{array}{l}\text { diurno (uso de instalações e atenção) } \\
\text { - Menos exigente quanto à aprendizagem e à } \\
\text { disciplina que o curso diurno } \\
\text { - Sistema de avaliação pouco exigente } \\
\text { - Proposta pedagógica, especialmente na } \\
\text { avaliação, está sendo distorcida } \\
\text { - Não prepara bem para o PAS e para o } \\
\text { "vestibular" }\end{array}$ \\
\hline
\end{tabular}

Obs.: os itens em negrito indicam declarações tanto dos grupos do ensino regular, quanto da educação de jovens e adultos. Os itens em itálico são afirmações dos grupos do ensino regular sobre a educação de jovens e adultos. PAS - Programa de Avaliação Seriada da Universidade de Brasília. 
Do lado das desvantagens, os pesquisados reconheceram que o ensino individualizado tinha seus limites. $O$ professor não atuava de modo tradicional, sendo comuns as reclamações quanto ao cansaço e a falta de atenção de alguns docentes ou, ainda, por não darem as respostas prontas e incentivarem a pesquisa. Com isso, o estudo dependia em grande parte do esforço e iniciativa dos alunos e do apoio dos colegas, como, aliás, é de esperar no ensino a distância e semipresencial. O mais grave, porém, foi que, se havia facilidade para aprovação, essa mesma facilidade resultava num estigma para o portador dos certificados. Como a escola não preparava adequadamente para o processo seletivo da educação superior, nem oferecia base para concursos públicos ou permitia acesso ao PAS, era difícil acalentar sonhos, como prosseguir os estudos, sobretudo na universidade pública e gratuita. A imagem social negativa era bem percebida por vários discentes, inclusive no mercado de trabalho:

Quem faz supletivo é tachado, fica com um mau histórico frente aos outros. (...) $\bigcirc$ conteúdo que é dado na escola não garante um bom emprego, isso vai depender de o aluno buscar sozinho e se esforçar mais. Aqui é muito acelerado e superficial, resumido, não dá para assimilar todo o conteúdo que deveria ser assimilado.

Quem faz supletivo está sempre para trás. (...) Vou fazer um concurso, (mas) eu não vou conseguir competir.

Outras dificuldades eram a falta de disciplina de alguns alunos, menos interessados e até com comportamentos desviantes, certas deficiências de infra-estrutura, além de uma controvérsia em relação à cooperativa, que, segundo alguns, vendia os materiais quase pelo mesmo preço do comércio local. Apesar dos desencontros, porém, a grande maioria dos participantes demonstrou gostar do estabelecimento e tinha uma visão relativamente otimista do próprio futuro, pretendendo continuar os estudos. De modo geral, estavam conscientes de que o seu crescimento dependia, em grande parte, do esforço individual.

\section{UM CARDÁPIO COM CUSTOS E BENEFÍCIOS VARIADOS?}

Os alunos participantes do estabelecimento de ensino médio regular noturno apresentavam em parte maiores interesses, ambições e expectativas, mostrando haver caminhos variados para alcançar diversos pontos de chegada. Também eles se concentravam na faixa etária até 25 anos, constituíam maioria os que exerciam ocupações não manuais, porém era menor a proporção de migrantes, embora a metodologia utilizada não permita afirmar se essas características eram repre- 
sentativas. Inexistência de escola na área rural de origem, falta de certidão de nascimento e de condições financeiras foram alguns dos motivos pelos quais não conseguiram escolaridade no passado ou a interromperam. A maioria já havia tido experiências de reprovação e abandono. A migração para o Distrito Federal, quando foi o caso, conduziu novamente aos estudos.

Os participantes dos grupos focais desse estabelecimento pareceram mais preocupados com a competição e a luta pela vida, bem como mais pragmáticos que os seus colegas do estabelecimento anterior. Assim, questionados sobre as suas motivações e o valor da educação, em sua maioria, referiram-se ao trabalho e à continuidade dos estudos, seguidos da realização pessoal e do valor da educação na inserção social geral, ao contrário da ênfase dos seus colegas da educação de jovens e adultos. Eis algumas das suas manifestações sobre o sentido de se educarem:

- Obter empregos via concursos.

- Ter condições de ser seletivo na hora de arranjar emprego.

- Ter um título e ser respeitado.

- Alcançar dignidade sem discriminação.

- Ter uma bagagem para poder falar com várias pessoas por igual sem ser criticada.

- Ter a condição de entender e fazer comparações, por exemplo, votar numa pessoa sem ser enganada com conversas tolas e promessas vazias.

Tendo em vista a seleção dos informantes, muitos haviam se transferido da educação de jovens e adultos para o ensino regular e alguns haviam passado dos turnos diurnos para o notuno, estes em virtude da idade e do trabalho e de menores exigências escolares. No caso dos primeiros, a trajetória foi comum: com repetência no ensino regular, deixaram por algum tempo de estudar e ingressaram na educação de jovens e adultos como meio de recuperar o tempo perdido e obter logo o certificado. No entanto, tendo aspirações a um ensino médio de melhor qualidade, transferiram-se para a modalidade regular, comemorando tal oportunidade:

O nível de ensino do supletivo é muito baixo e o conteúdo dado muito corrido. (...) É mais fácil, até porque tem menos conteúdo. (Mas) só tem vantagem como forma de acelerar o processo de seriação, tendo logo um diploma.

Vários participantes declararam que a educação de jovens e adultos passou por um período de declínio da qualidade, levando à sensação de perda de tempo e à migração para o ensino regular, como este: 
O supletivo teve um tempo que ele estava até bem, depois ele estava muito ruim. Aí eu parei e falei: agora vou fazer regular. Eu fiz um ano e pensei: meu Deus, eu não devia ter feito supletivo. Achei que tinha perdido tempo. Meu primeiro ano aqui (no estabelecimento de ensino regular) foi tudo o que aprendi, no ano passado...

Menores exigências, tempo acelerado, falta de acesso ao PAS e deficiências na preparação para o trabalho, para a educação superior e na base para os concursos públicos foram deficiências apontadas. Ainda assim, alguns alunos, pela dificuldade de conciliar horários de trabalho e estudo pretendiam regressar à educação de jovens e adultos. De modo geral, esta última havia sido uma plataforma para que os alunos se lançassem ao ensino regular mais exigente e não houve relatos de que estariam tendo dificuldades significativas nessa transição, ao contrário, sentiam-se satisfeitos com as suas exigências mais severas. Concordando, pois, com os participantes que cursavam o ensino médio na modalidade de educação de jovens e adultos, reconheciam como vantagens desta a facilidade de certificação em pouco tempo e a freqüência não obrigatória (Quadro I). Todavia, o ensino regular Ihes proporcionava "mais base", havia mais tempo disponível, o processo de ensino-aprendizagem era melhor, os estudantes, ainda que com certas exceções, precisavam ter mais compromisso. Além disso, suas aspirações de continuar os estudos em nível superior eram satisfeitas pela possibilidade de participar do PAS, além de a educação geral ministrada Ihes preparar melhor para o trabalho e para os concursos públicos. É interessante notar, aqui como nos reparos feitos à educação de jovens e adultos, que a educação geral tem um papel profissionalizante de relevância, embora não tenha esse rótulo. Além disso, a escola lhes respondia melhor aos anseios por um ensino tradicional, com o professor presente, explicando, orientando, incentivando e com um regime seriado que parecia proporcionar maior visão de conjunto do currículo, ao contrário do ensino individualizado. Algumas observações mostram a importância conferida ao estudo e também às formas mais usuais de executar o currículo, assim como as aspirações de continuar os estudos:

No regular aprende mais, porque tiro seis morrendo.

Os estudantes têm que ter mais compromisso, pois devem comparecer à escola todos os dias letivos.

Aprende-se as matérias em seqüência e com mais tempo para resolvermos as questões em sala de aula.

As poucas provas são feitas em blocos, são contextualizadas, o que é muito positivo para raciocinar e estabelecer relações com tudo. 
Podemos fazer inscrições para o PAS e o vestibular comum, tendo chances duplas de entrada para a universidade pública.

No entanto, nem tudo eram flores. Os informantes viam desigualdade de tratamento em relação ao ensino médio diurno, especialmente na falta de uso dos laboratórios, fato já constatado em pesquisa por amostragem junto aos alunos do ensino regular (Castro, Gomes, 2002). Também afirmaram haver menores exigências quanto à aprendizagem e à disciplina, além de fazer reparos quanto à eficácia da função propedêutica do ensino médio. A nova proposta pedagógica, com a avaliação mais voltada para trabalhos que para provas, segundo várias opiniões, estava sendo distorcida na prática e dever-se-ia voltar às provas tradicionais:

Gostaríamos de ser mais testados por provas por ser um critério mais justo e mostrar o perfil do aluno que estuda para valer. Trabalhos não medem nada e é perda de tempo. Um copia do outro. Os professores perdem o controle de tantos trabalhos, levando-se em consideração o número de alunos por sala e o número de turmas que cada um dá aulas.

Quanto aos professores, a discriminação (em relação ao turno da noite) começa a existir quando baixam o nível de ensino. Facilitam demais, argumentando que os alunos trabalham e chegam cansados.

Há muito paternalismo. Parece que os professores do noturno disfarçam o seu cansaço junto com os alunos, pois a maioria trabalha em outros empregos.

No entanto, em contradição com as suas reivindicações, vários alunos reconheceram que teriam dificuldades de acompanhar o ensino regular se as exigências fossem elevadas, o que dá uma idéia dos dilemas vividos nas salas de aula: "O grau de dificuldade não poderia ser aumentado, uma vez que muitos colegas não conseguiriam acompanhar e muitos desistiriam".

Como conseqüência, vários dos alunos se culpavam profundamente pelo sucesso ou fracasso escolar. Quando refletiam a respeito das desvantagens do ensino noturno, voltavam à afirmaç̧ão de que o esforço individual levaria a vencer essas mesmas dificuldades. Entretanto, alguns chegaram a propor que, se a educação de jovens e adultos facilita a discriminação dos seus alunos, era preciso modificá-la até ao âmago da sua filosofia.

Tendo como sonho mais alto (e distante) ingressar na educação superior pública e gratuita, já que os seus recursos eram escassos para pagar mensalidades, ocasionando-lhes grande angústia, a preocupação com o futuro e a continuidade dos estudos era uma constante. $\bigcirc$ rigor desse processo, bem como o do mercado de 
trabalho, era responsável pelas preocupações com a qualidade. A diferenciação desta última no sistema educacional permitiu-lhes delinear uma hierarquia de oportunidades educacionais, relacionadas à competitividade prática para enfrentar os gargalos de seleção na vida escolar e fora dela. Na sua perspectiva, o ensino particular e o ensino regular diurno têm as melhores condições de sucesso, em detrimento do ensino público, noturno e da educação de jovens e adultos (Quadro 2). Esses critérios se combinam, atenuando ou agravando as condições de êxito. Desse modo, o ensino regular público diurno seria melhor que o noturno, assim como o segundo seria melhor que a educação de jovens e adultos. É interessante observar que os participantes da instituição de educação de jovens e adultos, com expectativas menores, não suscitaram tal hierarquia nem, em algum momento, levantaram a possibilidade de transferir-se para o ensino regular, em vista das deficiências e do estigma da modalidade de educação que cursavam.

QUADRO 2

HIERARQUIZAÇÃO DAS OPORTUNIDADES EDUCACIONAIS SEGUNDO O PRESTÍGIO ATRIBUIIDO PELOS PARTICIPANTES

\begin{tabular}{|c|c|}
\hline \multirow{2}{*}{ Turnos } & Diurno \\
\cline { 2 - 2 } & Noturno \\
\hline \multirow{2}{*}{ Modalidades } & Ensino regular \\
\cline { 2 - 2 } & Educação de jovens e adultos \\
\hline \multirow{2}{*}{ Dependência administrativa } & Particular \\
\cline { 2 - 2 } & Pública \\
\hline
\end{tabular}

\section{CAMINHOS E PONTOS DE CHEGADA DIFERENTES}

Como as diversidades são hierarquizadas no âmbito do sistema educacional e da sociedade, os resultados confirmam a estratificação das duas modalidades de educação em foco neste artigo, o ensino regular e a educação de jovens e adultos. $\bigcirc$ ideal democrático prevê caminhos diferentes para o mesmo ponto de chegada, com a finalidade de contemplar as diferenças grupais e individuais, integrando todos em condições de sucesso escolar. No entanto, a pesquisa aponta uma ordenação de oportunidades educacionais, pela qual caminhos diferentes levam a pontos de che- 
gada também diferentes. Em vez da democratização de oportunidades educacionais, visando à igualdade de condições de êxito, delineia-se um cardápio com custos e benefícios variados. Assim, a educação de jovens e adultos, segundo os pesquisados, seria o âmbito escolhido pelos que queriam ou podiam menos e também obtinham menos. A custos menores, em termos de esforço e provavelmente de valores despendidos por aluno, correspondiam certificados de menor prestígio, suscetíveis de ser aceitos com reserva ou ser recusados pelo mercado de trabalho, além de possibilidades mais modestas de continuidade dos estudos. Para os que perderam o bonde da escolaridade regular, mas que se dispunham a um sacrifício maior no ensino regular, com mais rigor e mais possibilidades de futuro, eram conferidos certificados aceitos com menor reserva, apesar de a sua data indicar que os seus portadores estavam defasados em termos de idade. Para os que conseguiram manter-se em dia com o bonde da escolaridade regular, completando os seus estudos nos períodos diurnos, antes das pressões de ingresso no trabalho, provavelmente havia maiores perspectivas para os estudos superiores e a atividade laboral. De certa forma, é o chamado "efeito Mateus": dar mais a quem tem mais e menos a quem tem menos. É assim que a educação até pode exercer um efeito democratizador, mas poderia amplificá-lo e maximizá-lo muito mais, contribuindo para a redução de disparidades.

O valor atribuído aos certificados, tanto pela sociedade quanto pelos alunos, remete à perspectiva do credencialismo, da moeda que serve para a luta por riqueza, prestígio social e poder. No entanto, essa moeda apresenta um valor facial relativo, visto que os pesquisados tinham consciência do valor intrínseco que ela deveria representar, em termos de competências. Com efeito, preocupados com o mercado de trabalho e a continuidade dos estudos, parte dos participantes, independentemente das facilidades legais, escolhia o caminho mais árduo, isto é, o do ensino regular noturno. Esta é uma pista para entender as estatísticas nacionais já apontadas, que mostram a retenção do alunado nesse mesmo ensino regular, migrando para o turno da noite. Parece, pois, que o credencialismo é relativo e que o "facilitário" dos certificados e diplomas, por força das exigências sociais e econômicas, tem alcance limitado, o que é positivo num país em que escândalos de corrupção emergem constantemente na mídia.

Os dados, ainda que restritos, também confirmam a precariedade dos valores da educação de jovens e adultos, o seu menor grau de legitimidade e a sua possível maior dificuldade de obtenção de recursos. Esta última, independentemente dos elogiáveis aspectos pedagógicos, pode sugerir uma explicação para a ampla adoção do ensino semipresencial no país, cujo custo/aluno é reconhecidamente mais baixo que o do ensino presencial. É também reiterada a dualidade de sistemas edu- 
cacionais, com a "escola para os nossos filhos" e a "escola para os filhos dos outros", que se tentava evitar em 1971. As políticas públicas, ao longo dos anos, não conseguiram superar essa dualidade, nem evitar a competição entre ambos os sistemas ou a posição de inferioridade da escola noturna. Em outros termos, a educação de jovens e adultos continuou separada e alojada num nicho menor. Portanto, os resultados sugerem que a educação de jovens e adultos é uma alternativa negligenciada de democratização educacional no Brasil e que isso ocorre pela consciência dos seus limitados qualidade e retorno. Por ser ruim, deixa de cumprir integralmente o seu papel. Para torná-la uma alternativa efetiva, falta colocar em prática políticas públicas que deixem de devolver menos a quem tem menos. Assim, o temor mais infundado é o da correria ao "facilitário" e o mais grave e fundamentado é o de a educação de jovens e adultos não fazer o que lhe cabe.

\section{REFERÊNCIAS BIBLIOGRÁFICAS}

BERNSTEIN, B. Class, codes and control. Londres: Routledge and Kegan Paul, v. 3: Towards a theory of educational transmissions, 1977.

Class, codes and control. Londres: Routledge and Kegan Paul, v. 4: The structuring of pedagogic discourse, 1977.

BOURDIEU, P.; PASSERON, J. C. La Reproduction: éléments pour une théorie du système d'enseignement. Paris: Minuit, 1970.

BOWLES, S.; GINTIS, H. Schooling in capitalist America: educational reform and the contradictions of economic life. New York: Basic, 1977.

BRASIL. Congresso Nacional. Plano nacional de educação. Brasília: Senado Federal; Unesco, 2001.

BRASIL. Ministério da Educação. Instituto Nacional de Estudos e Pesquisas Educacionais. Censo Escolar 1997.Brasilia: 1998.

. Censo Escolar 1998.Brasília: 1999.

Censo Escolar 1999. Brasília: 2000.

Censo Escolar 2000. Brasília: 200 Ia.

Censo Escolar 200 I.Brasília: 2002.

CÂMARA, J. da S. Rethinking education towards change and world diversity. In: INTERNATIONAL COUNCIL ON EDUCATION FOR TEACHING. Teacher Education in the New Millenium: the quest for essence. Windhoek: Icet, 2000. v. I, p.3 I0-3।8. 
CASTRO, P. E. M. de; GOMES, C. A. A Utilização do tempo pelo aluno do ensino médio público. Psicologia da Educação. São Paulo, n. 12, p.69-88, 2002.

CAVALCANTE, A. F. Ensino público: gratuito, em termos - custos indiretos do ensino médio para os alunos das escolas públicas do Distrito Federal. Em Aberto. Brasília, v. 19, n. 75, p. I3- 122, jul. 2002.

CLARK, B. R. Adaptação das organizações e valores precários. In: ETZIONI, A. Organizações complexas. estudo das organizações em face dos problemas sociais. São Paulo: Atlas, 1978. p. $161-168$.

COLLINS, R. The Credential society. an historical sociology of education and stratification. New York: Academic, 1979.

DIAS, J. A. et al. Ensino médio e estrutura sócio-econômica: Estado de São Paulo. Rio de Janeiro: Inep, 1967.

FILMUS, D. et al. Ensino médio: cada vez mais necessário, cada vez mais insuficiente. Brasília: Unesco; MEC, Semtec, 2002.

FLETCHER, P. R.; RIBEIRO, S. C. O Ensino de primeiro grau no Brasil de hoje. Brasília: Ipea, 1987.

FUNDAÇÃO INSTITUTO BRASILEIRO DE GEOGRAFIA E ESTATÍSTICA. Censo Demográfico de 2000. Disponível em: <http://wnw.ibge.gov.br>. Acesso em: 2 fev. 2003.

GIROUX, H. Teoria crítica e resistência em educação: para além das teorias da reprodução. Petrópolis: Vozes, 1986.

GOMES, C. A. A educação em perspectiva sociológica. 3. ed. São Paulo: EPU, 1994.

GOMES, C. A.; CARNIELLI, B.; ASSUNÇÃO, I. R. Avaliação em educação de jovens e adultos: entre o rigorismo e a permissividade, São Paulo, 2002. [Trabalho apresentado no Congresso Internacional sobre Educação de Jovens e Adultos: Fortalecendo a inclusão social. Alfabetização Solidária e Unesco].

HADDAD, S. Ensino supletivo no Brasil: o estado da arte. Brasília: Inep; Rede Latino-Americana de Informação e Documentação em Educação, 1987.

HADDAD, S. et al. Educação de jovens e adultos ( 1986 - 1998) Brasília: MEC/Inep/Comped, 2002. (Série Estado do Conhecimento, n. 8)

MORROW, R. A.; TORRES, C. A. Social theory and education: a critique of theories of social and cultural reproduction. Albany, New York: State University of New York, 1995.

SNYDERS, G. Pedagogia progressista. Coimbra: Almedina, 1974.

UNESCO. International expert meeting on general secondary education in the twenty-first century. trends, challenges and priorities: final report. Beijing: People's Republic of China, 2I 25 May 2001. 
WEBER, Max. Economy and society. an outline of interpretative sociology. New York: Bedminster, 1968.

YOUNG, M. F. D. An Approach to the study of curriculum as socially organized knowledge. In: . (org.). Knowledge and control: new directions for the sociology of education. Londres: Collier MacMillan, 197I. p. 19-46.

Curriculum and democracy. lessons from a critique of the "new sociology of education". Londres: University of London, 1988.

Recebido em: fevereiro 2003

Aprovado para publicação em: março 2003 